\title{
Temperature Dependence of Structural and Optical Properties of ZnO Nanoparticles Formed by Simple Precipitation Method
}

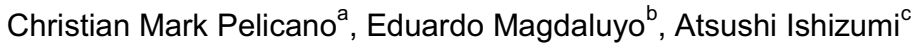 \\ ${ }^{a, b}$ Department of Mining, Metallurgical and Materials Engineering, University of the Philippines, Quezon City Philippines \\ ${ }^{\circ}$ Graduate School of Materials Science, Nara Institute of Science and Technology, Ikoma Nara Japan
}

\begin{abstract}
ZnO}$ nanoparticles were successfully synthesized by a simple precipitation method. The effect of growth temperature on the structural and optical properties of the resulting nanoparticles was investigated by transmission electron microscopy (TEM), ultraviolet-visible spectroscopy (UV-VIS) and photoluminescence (PL) spectroscopy. TEM images and selected area electron diffraction (SAED) pattern showed that the nanoparticles were polycrystalline $\mathrm{ZnO}$ having hexagonal wurtzite structure. The average size of the nanoparticles were $4.72 \mathrm{~nm}$ to $7.61 \mathrm{~nm}$ synthesized at room temperature to $80^{\circ} \mathrm{C}$. This result is also consistent with the calculated sizes using effective-mass approximation model. From the optical absorption data, the band gap energy of nanoparticles blue-shifted due to the quantum confinement.
\end{abstract}

\section{Introduction}

Particles of semiconductor materials in nanoscale have recently gained much interest due to their unique physical and chemical properties, which are different from the bulk materials. Among these materials, $\mathrm{ZnO}$ nanoparticles have been consistently studied due to its several possible applications in sensors [1], catalysis [2], photovoltaics [3-4] and piezoelectric transducers [5], among others. $\mathrm{ZnO}$ is an n-type semiconductor with a direct wide band gap of $3.37 \mathrm{eV}$ and a large exciton binding energy of about $60 \mathrm{meV}$ at room temperature [6]. It also has a high absorption coefficient, good carrier mobility and flexible synthesis techniques. The properties of nanostructured $\mathrm{ZnO}$ depend strongly on its structural morphology and crystal size [7]. Thus, a deep understanding of these properties is necessary for fundamental study and utilization for commercial applications.

Various synthesis methods have already been developed for $\mathrm{ZnO}$ nanoparticles such as metal organic chemical vapor deposition (MOVCD) [8], sol-gel [9], flame spray pyrolysis [10], thermal decomposition [11] and precipitation [12]. However, these methods require controlled reaction systems such as high temperature, high cost materials and complicated equipment [13] except for the precipitation route which offers a simple and economical method for large scale production.

In this study, a simple precipitation method was utilized to synthesize $\mathrm{ZnO}$ nanoparticles. The effect of growth temperature to the structural and optical properties of the resulting nanoparticles was also examined using transmission electron microscope (TEM), (UV-VIS) and photoluminescence (PL) spectroscopy.

\section{Experimental}

Dimethyl sulfoxide (DMSO, $\left.\left(\mathrm{CH}_{3}\right)_{2} \mathrm{SO}\right)$ and ethanol $\left(\mathrm{CH}_{3} \mathrm{CH}_{2} \mathrm{OH}, 99.5 \%\right)$ were used as solvents; zinc acetate dehydrate $\left(\mathrm{Zn}\left(\mathrm{CH}_{3} \mathrm{CO}_{2}\right)_{2} \cdot 2 \mathrm{H}_{2} \mathrm{O}\right)$ as precursor; tetramethylammonium hydroxide $\left(\mathrm{N}(\mathrm{Me})_{4} \mathrm{OH} \cdot 5 \mathrm{H}_{2} \mathrm{O}\right)$ for hydrolysis. In a typical preparation, $6 \mathrm{ml}$ of $0.55 \mathrm{M}$ $\mathrm{N}(\mathrm{Me})_{4} \mathrm{OH}$ in ethanol was added dropwise at approximately $0.6 \mathrm{~mL} / \mathrm{min}$ to $0.1 \mathrm{M} \mathrm{Zn}\left(\mathrm{CH}_{3} \mathrm{CO}_{2}\right)_{2} \cdot 2 \mathrm{H}_{2} \mathrm{O}$ dissolved in DMSO under constant stirring. The nanoparticles were precipitated and washed twice by centrifugation for $30 \mathrm{~min}$ in ethyl acetate to eliminate excess reactants. After which the nanoparticles were redissolved in $3 \mathrm{ml}$ ethanol for storage. The morphology and structure of $\mathrm{ZnO}$ nanoparticles were examined by transmission electron microscope (TEM, JEM-3100FEF) and selected area diffraction (SAED). For optical characterization, the UV-VIS transmittance and photoluminescence (PL) spectra were measured by JASCO V-530 and FP 750 spectrometer, respectively.

\section{Results and discussion}

Figure 1 shows the TEM images of $\mathrm{ZnO}$ nanocrystals formed at different temperatures. At room temperature, monodispersed $\mathrm{ZnO}$ nanocrystals with a mean diameter of $4.72 \mathrm{~nm}$ were formed as seen in Figure 1(a). Increasing the temperature to $40^{\circ} \mathrm{C}$, the mean diameter of the

Corresponding author: ${ }^{\mathrm{a}}$ copelicano@upd.edu.ph, ${ }^{\mathrm{b}}$ edmagdaluyo@gmail.com 
nanocrystals increased to about $5.24 \mathrm{~nm}$. As can be observed, the particles have started to agglomerate due to Oswald ripening process which could be induced by increasing supply of thermal energy. At higher temperatures of $60^{\circ} \mathrm{C}$ and $80^{\circ} \mathrm{C}$, larger particles with mean diameters of 6.70 and $7.61 \mathrm{~nm}$ developed, respectively, as seen in Figure 1(c) and 1(d). When the growth temperature is increased the critical particle radius increased as well resulting to the disappearance of the smaller particles to supplement the growth of the larger ones [14]. Here, the following chemical reactions govern the growth stages of $\mathrm{ZnO}$ nanoparticles:

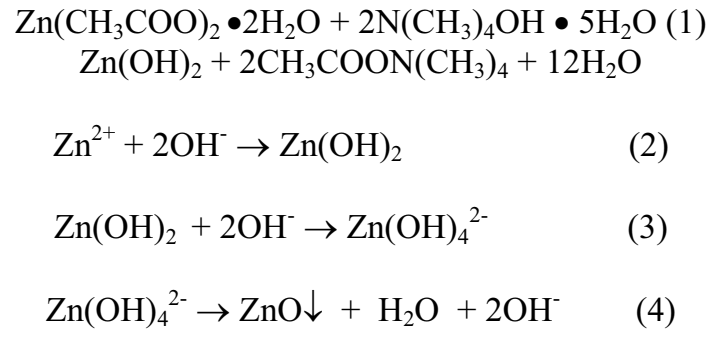

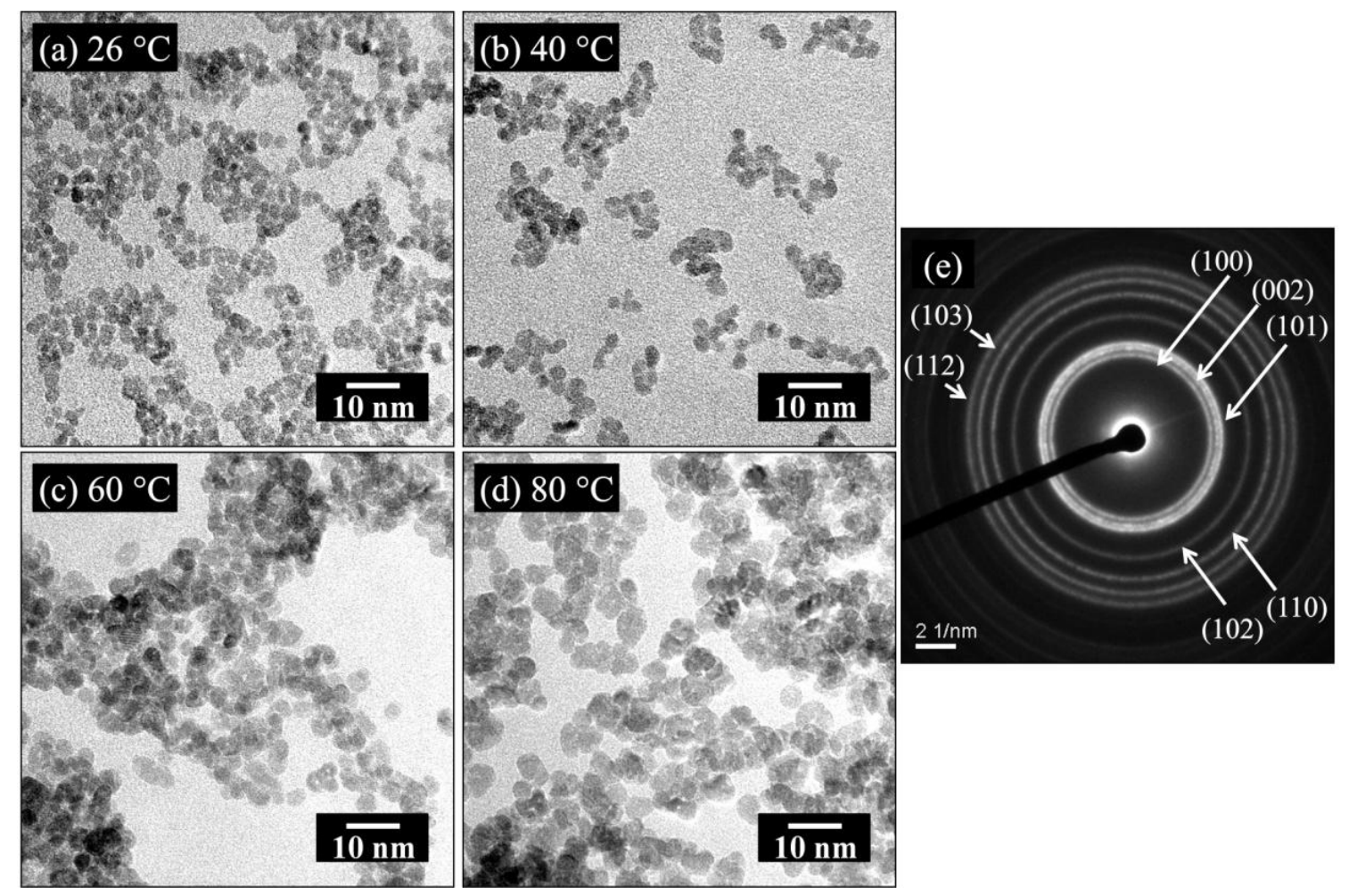

Figure 1. TEM images of $\mathrm{ZnO}$ nanocrystals synthesized at different temperatures: (a) $26^{\circ} \mathrm{C}$, (b) $40^{\circ} \mathrm{C}$, (c) $60^{\circ} \mathrm{C}$, (d) $80^{\circ} \mathrm{C}$ and (e) SAED pattern for $80^{\circ} \mathrm{C}$ sample

When the $\mathrm{N}(\mathrm{Me})_{4} \mathrm{OH} \cdot 5 \mathrm{H}_{2} \mathrm{O}$ in ethanolic solution was slowly added into the $\mathrm{Zn}\left(\mathrm{CH}_{3} \mathrm{CO}_{2}\right)_{2} \cdot 2 \mathrm{H}_{2} \mathrm{O}$ in DMSO solution, $\mathrm{Zn}(\mathrm{OH})_{2}$ precipitated instantaneously, as illustrated reaction (2). Further addition of hydroxyl ions $\left(\mathrm{OH}^{-}\right)$resulted in the conversion of $\mathrm{Zn}(\mathrm{OH})_{2}$ into soluble $\mathrm{Zn}(\mathrm{OH})_{4}{ }^{2-}$. As the reaction proceeded, $\mathrm{Zn}(\mathrm{OH})_{4}{ }^{2-}$ is dehydrated into $\mathrm{ZnO}$ following crystal growth. Figure 2 shows the UV-VIS absorption spectra of the synthesized $\mathrm{ZnO}$ nanocrystals for different temperatures. As the reaction temperature is decreased, the characteristic absorption peaks of the synthesized $\mathrm{ZnO}$ nanocrystals blue-shifted from 3.54 to $3.71 \mathrm{eV}$ due to quantum confinement effect. On the other hand, these energy band gap values can be used to calculate estimation of size variation from the absorption spectra through the effective mass approximation model [15]:

$$
E_{g}^{*}=E_{g}^{B u l k}-R_{y}^{*}+\frac{2 \pi^{2} \hbar^{2}}{M D^{2}}
$$

where $\mathrm{E}_{\mathrm{g}}{ }^{\mathrm{Bulk}}=3.37 \mathrm{eV}$ is the energy of band gap of the bulk $\mathrm{ZnO}, \mathrm{M}$ is the effective mass, $\hbar$ is Planck's constant, $\mathrm{R}_{\mathrm{y}}{ }^{*}=0.04 \mathrm{eV}$ is the Rydberg's constant, $\mathrm{D}$ is the diameter of the nanoparticles and $\mathrm{E}_{\mathrm{g}}{ }^{*}$ is the energy band gap in $\mathrm{eV}$ that can be calculated from the excitonic absorption peak using Equation 6:

$$
E_{g}^{*}=\frac{1240}{\lambda_{\text {excitonic }}}
$$

Table 1. Measured and calculated nanoparticle size aBy UVVIS, bBy TEM

\begin{tabular}{cccc}
\hline $\begin{array}{c}\text { Temperature } \\
\left({ }^{\circ} \mathbf{C}\right)\end{array}$ & $\begin{array}{c}\text { Band } \\
\text { Gap }(\mathbf{e V})\end{array}$ & $\begin{array}{c}\text { Diameter } \\
\text { Size }^{\mathbf{a}}(\mathbf{n m})\end{array}$ & $\begin{array}{c}\text { Diameter } \\
\text { Size }^{\mathbf{b}}(\mathbf{n m})\end{array}$ \\
\hline 26 & 3.71 & 5.86 & 4.72 \\
40 & 3.60 & 6.88 & 5.24 \\
60 & 3.57 & 7.27 & 6.70 \\
80 & 3.54 & 7.73 & 7.61 \\
\hline
\end{tabular}


The size values using the effective mass model are given in Table 1. The results are in agreement with those measured using TEM having the same trend of increasing size as growth temperature is increased. Figure 3 shows the PL spectra of the $\mathrm{ZnO}$ nanoparticles at different temperatures. It has been well established that nanostructured $\mathrm{ZnO}$ with small size and defects demonstrates strong visible emission [17] attributed to defects such as oxygen $\left(\mathrm{V}_{\mathrm{o}}{ }^{\prime \prime}\right)$ and zinc $\left(\mathrm{Zn}_{\mathrm{i}}\right)$ interstitials. Here, only a strong visible emission can be observed at room temperature synthesis. At the same time large size and crystalline in nature nanoparticles exhibit stronger UV emission [16] which is related to a near band-edge transition of $\mathrm{ZnO}$, specifically, the recombination of the free excitons. When the temperature is increased to $40^{\circ} \mathrm{C}$ and $60^{\circ} \mathrm{C}$, both UV and visible emissions can be seen due to the development of larger particles in this temperature regime. Defects present decreased as the surface area of the nanoparticles increased due to Ostwald ripening. At reaction temperature of $80^{\circ} \mathrm{C}$, only $\mathrm{UV}$ emission was observed and could indicate increased crystallinity of the nanoparticles. It should be noted that the emission peaks also red-shifted to higher wavelength supporting the earlier results of an increase in the diameter of the nanoparticles at higher temperatures.

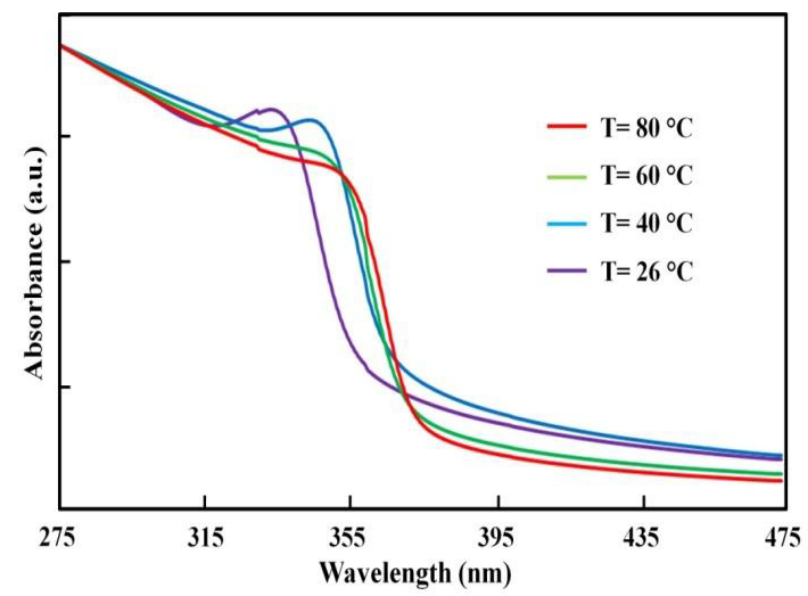

Figure 2. UV-VIS Absortion spectra of $\mathrm{ZnO}$ nanoparticles synthesized at different temperatures

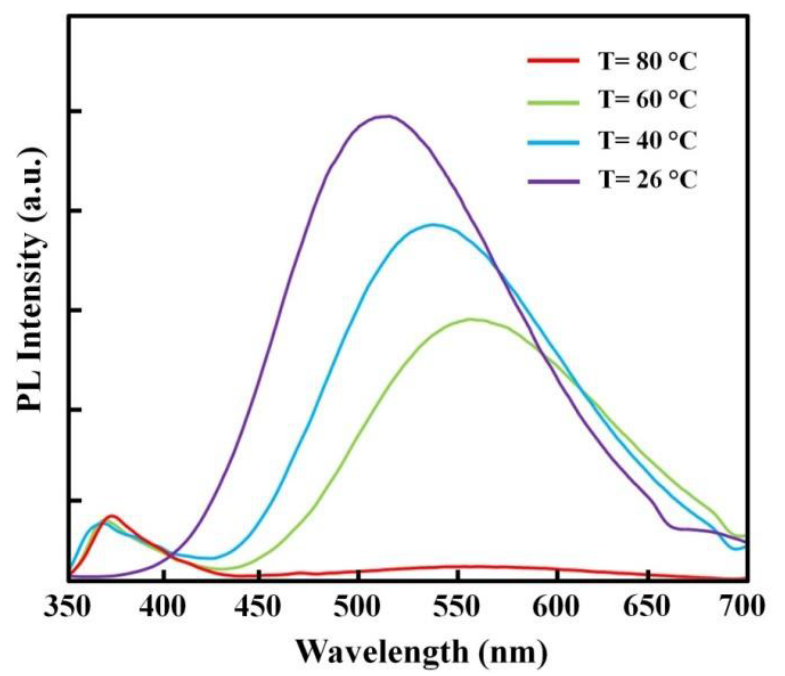

Figure 3. Photoluminescence spectra of $\mathrm{ZnO}$ nanocrystals for different temperatures

\section{Summary}

We demonstrated a simple precipitation method for the preparation of $\mathrm{ZnO}$ nanoparticles using zinc acetate and tetramethylammonium hydroxide as precursors. The particles were hexagonal $\mathrm{ZnO}$ with average sizes of 4.72$7.61 \mathrm{~nm}$ for increasing reaction temperatures. This trend is consistent from calculations using effective mass approximation model. From absorption data, the band gap values blue-shifted to lower temperatures revealing quantum confinement at smaller diameters. These sizecontrolled properties of $\mathrm{ZnO}$ nanoparticles exhibit good utilization for various commercial applications.

\section{References}

1. Haiqin Bian et al.," Improvement of acetone gas sensing performance of $\mathrm{ZnO}$ nanoparticles", Journal of Alloys and Compounds 658 (2016) 629e635

2. Chayma Abed et al.," Mg doping induced high structural quality of sol-gel $\mathrm{ZnO}$ nanocrystals: Application in photocatalysis", Applied Surface Science 349 (2015) 855-863

3. E. Gondek et al.,"Organic hybrid solar cellsInfluence of $\mathrm{ZnO}$ nanoparticles on the photovoltaic efficiency", Materials Letters 131 (2014) 259-261

4. Muhammad Ikram et al.," Hybrid organic solar cells using both $\mathrm{ZnO}$ and PCBM as electron acceptor materials", Materials Science and Engineering B 189 (2014) 64-69

5. Van Son Nguyen et al.," Influence of cluster size and surface functionalization of $\mathrm{ZnO}$ nanoparticles on the morphology, thermomechanical and piezoelectric properties of P(VDF-TrFE) nanocomposite films", Applied Surface Science 279 (2013) 204-211

6. Y. I. Ozgur, Alivov, C. Liu et al., "A comprehensive review of $\mathrm{ZnO}$ materials and devices," J. Appl. Phys,98 (2005), 1-103.

7. J. Z.Yin, et al., Water Amount Dependence on Morphologies and Properties of $\mathrm{ZnO}$ nanostructures in Double-solvent System. Sci. Rep. 4, 3736.

8. Jie Jiang et al.," Effects of phosphorus doping in $\mathrm{ZnO}$ nanocrystals by metal organic chemical vapor deposition", Materials Letters 68 (2012) 258-260

9. E Moghaddam et al.," Preparation of surfacemodified $\mathrm{ZnO}$ quantum dots through an ultrasound assisted sol-gel process", Applied Surface Science 346 (2015) 111-114

10. Okorn Mekasuwandumrong et al.," Effects of synthesis conditions and annealing post-treatment on the photocatalytic activities of $\mathrm{ZnO}$ nanoparticles in the degradation of methylene blue dye", Chemical Engineering Journal 164 (2010) 77-84

11. Mutasim I. Khalil et al.,'Synthesis and characterization of $\mathrm{ZnO}$ nanoparticles by thermal decomposition of a curcumin zinc complex", Arabian Journal of Chemistry (2014) 7, 1178-1184 
12. K. Jeyasubramaniana,, G.S. Hikkua, R. Krishna Sharma,"Photo-catalytic degradation of methyl violet dye using zinc oxide nano particles prepared by a novel precipitation method and its anti-bacterial activities", Journal of Water Process Engineering 8 (2015) 35-44

13. C.Wang,W.X. Zhang, X.F. Qian, X.M. Zhang, Y. Xie, Y.T. Qian, A room temperature chemical route to nanocrystalline $\mathrm{PbS}$ semiconductor, Mater. Lett. 40 (1999) 255-258.

14. Ronald Buckley,"Solid State Chemistry Research trends", Nova Science Publishers Inc., 2007

15. L.E. Brus, J. Chem. Phys. 80 (1984) 4403.

16. Sun, T. J.; Qiu, J. S.; Liang, C. H. J. Phys. Chem. C 2008, 112, 715-721.

17. Djuris 'ic', A. B.; Choy, W. C. H.; Roy, V. A. L.; Leung, Y. H.; Kwong, C. Y.; Cheah, K. W.; Rao, T. K. G.; Chan, W. K.; Surya, C. AdV. Funct. Mater. 2004, 14, 856-864. 